\title{
Unlocking the Cultural Diversity Black Box: Application of Culturally Responsive Pedagogies in University Classrooms in Zimbabwe
}

\author{
Norman Rudhumbu* \\ Bindura University of Science Education, Zimbabwe \\ https://orcid.org/0000-0002-2536-5511
}

\begin{abstract}
The study investigated the mediating role of lecturers' biographic factors and multicultural competences in the use of Culturally Responsive Pedagogies (CRPs) to effectively teach culturally diverse classrooms in universities. Studies show that culture has an influence on student learning and that if it is not effectively managed, it can affect how students learn. The study employed a quantitative approach that used structured questionnaires for data collection from a sample of 370 lecturers selected from six universities using a stratified random sampling strategy. Principal Component Analysis (PCA) was used for data purification. Data were analyzed using descriptive statistics, Oneway ANOVA, multiple regression analysis, and correlation analysis. Results showed that verbal and non-verbal communication, cultural knowledge, classroom management, and student-teacher interaction significantly influenced the application of CRPs by university lecturers. It also emerged from the study that the application of CRPs has a significant effect on diversity management in universities. Results further showed that the use of CRPs by university lecturers is still work in progress due to a myriad of challenges they face chief among which is a lack of cultural competence skills. These results have implications to diversity management in university classrooms in particular as well as in universities in general.
\end{abstract}

Keywords: Culturally responsive pedagogy; cultural diversity; diversity management; multicultural competences; classroom management; cultural knowledge

\section{Introduction}

The purpose of the study was to establish how the university use CRPs to manage diversity in university classrooms. The level of cultural heterogeneity in university classrooms has become very high hence the need to manage diversity in today's classrooms in order to ensure effective teaching and learning has

\footnotetext{
* Corresponding author: Norman Rudhumbu; Email: nrudhumbu@buse.ac.zW
} 
become a must. Various studies show that university classrooms of today are characterized by a diverse range of students in terms of the cultural backgrounds (Wah \& Nasri, 2019). Discriminatory teaching practices in these classrooms however continue to have a negative influence on learning experiences of many students that are referred to as others and are always othered (Taylor, 2018; Wah \& Nasri, 2019). At a general level, cultural differences are viewed in terms of differences in race, ethnicity, religion, language, economic status, and sexual orientation (Klen, 2015). Cultural differences in classrooms which affect how students learn include differences in language, dress, assertiveness, collectivism, performance orientation, competitiveness, future orientation, power distance and risk avoidance among others (Levonius, 2016). These factors define and shape how students learn behave, communicate, and interact with others in the classroom (Klen, 2015). Culturally Responsive Pedagogy (CRPs) can therefore be used to navigate these differences and the challenge of managing diversity in classrooms. As a result, the need for university lecturers to be aware of cultural differences among their students can be viewed as being very important for effective teaching (Byrd, 2016; Maasum et al, 2014; Tarasawa, 2018). This means that there is a need for lecturers to have a certain level of multi-cultural competence for them to be able to deal with issues of cultural diversity in their classrooms through the use of culturally responsive pedagogies.

The literature shows that a number of resource pedagogies arose during the 1970s through to the 1990s aimed at finding the intersection between pedagogy, culture and language (Richardson, 2018) and one such pedagogical point of intersection was the culturally responsive pedagogy (CRPs) (Diaz, Suarez \& Valencia, 2019; Wah \& Nasri, 2019). CRP is defined as a teaching approach that employs cultural knowledge, prior experience, frames of references, and performance styles and measures of cultural diversity in students to make learning encounters more relevant to and effective for the students (Chinn, 2017; Powell et al, 2016). The study was guided by the following research questions:

RQ1. What factors influence the implementation of CRPs in universities?

RQ2. What are the barriers to effective implementation of CRPs in universities?

RQ3. How significantly does the application of CRPs contribute to diversity management in universities?

\section{Literature review}

\subsection{Culture and Culturally Responsive Pedagogies}

Culture has an influence on student learning and social adjustment and is defined by Hitchcock, Prater and Chang (2009: 2) as "the shared learned meanings and behaviours derived from living within a particular life activity" which according to Maasum et al (2014) and Dorrington and Guy (2018), encompasses various aspects that include customs and values, traditions, communication, attitudes, beliefs, learning styles, rituals, behaviours as well as language. CRPs have been consistently associated with various positive student academic outcomes such as improved academic performance, development of positive attitudes and a sense of self-awareness (Brown, 2019; Ladson-Billing, 2014; Paris, 2012). Responsive, according to Dorrington and Guy (2018), means to react quickly and positively, to respond with interest and enthusiasm, hence connotes receptiveness and 
eagerness. CRPs also known as culturally appropriate pedagogies (CAPs) therefore refers to a pedagogy that enables lecturers in universities to "quickly and positively respond with interest and enthusiasm to the diverse cultures of students" (Dorrington \& Guy, 2018: 5). CRPs by definition are teaching approaches that use cultural characteristics, experiences and perspectives of culturally diverse students as catalysts for effective teaching (Cho, 2017; Kahu \& Nelson, 2018; Maasum et al, 2014; Richardson, 2018).

\subsection{Research model and hypotheses formulation}

The study is informed by the symbolic interactionist theory which developed by Cooley (1902) and further improved by Mead (1934) among others. Interactionism also called the symbolic interactionist theory or perspective is predicated on the idea that in a social context, individuals create meanings and then act in some way based on these subjective meanings (Essays UK, 2017). Verbal communication in which words are the predominant symbols is key to subjective meaning making (subjective interpretation) evident in social interactions in social contexts which lead to different emotions (positive and negative) in people. These emotions result in different ways of behaving and acting that have an influence, in the context of classrooms, on continued participation in learning by students (Barker, Nyberg \& Larsson, 2019). Subjective interpretations from a social context such as a classroom can contribute to positive emotions such as pleasure and excitement which facilitate learning or to negative emotions such as worry, nervousness, and shame among others, which disrupt learning (Fitzpatrick, 2018; Frydendal \& Thing, 2019; Lodewyk \& Muir, 2017; Simonton \& Garn, 2018; Wrench \& Garrett, 2015). In a nutshell, the symbolic interactionist theory argues that people behave and act the way they do because of the meanings they attach to communicative stimuli from a social context such as a classroom.

In the context of the current study, Figure 1 shows that the symbolic interaction theory helps to inform lecturers in university classrooms about how certain behaviours, actions, assumptions and expectations by them and students affect how learning progresses in culturally diverse classrooms, especially with regards to the quality of teacher-student interaction as well as student-student interaction. A study by Krasnoff (2016) found opportunities for discussion sessions as well as flexible groupings provide students opportunities for them to interact between themselves as well as with the teachers thus ensuring that students of diverse cultures are able to contribute to lessons. 


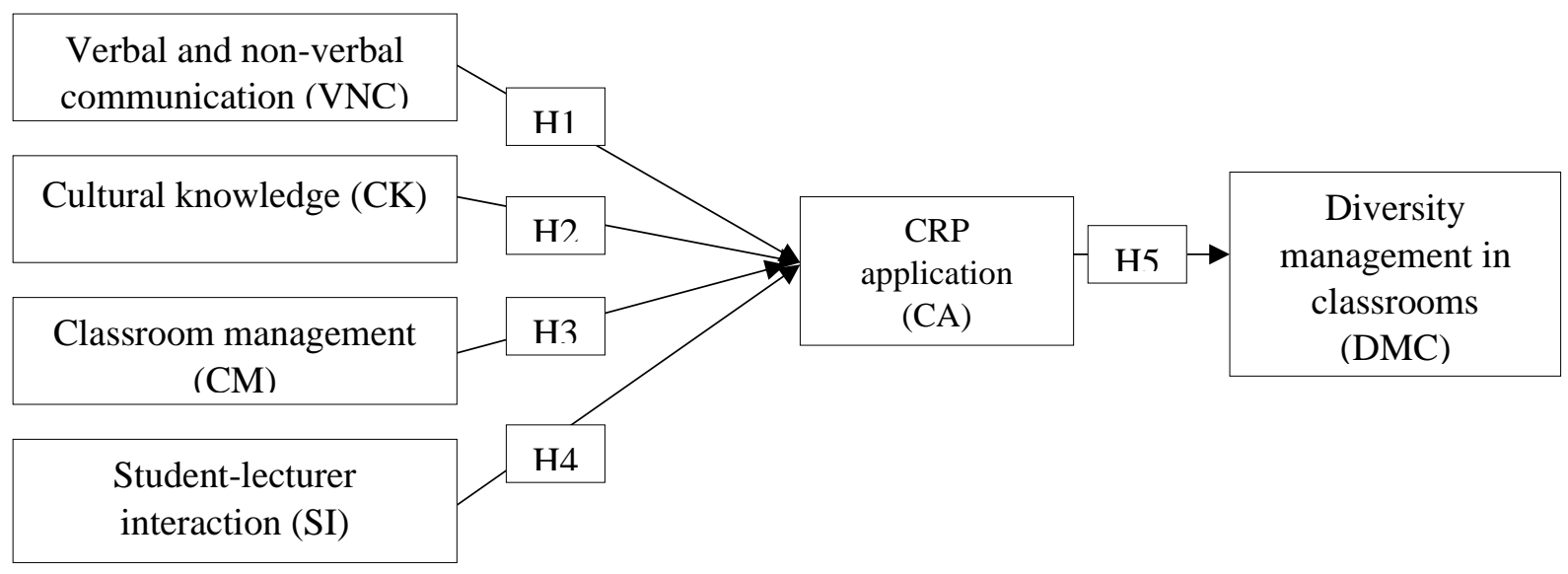

Figure 1: Research model adapted from the symbolic interactionist theory (Cooley (1902) and Mead (1934)

In their separate studies, Ritzer (2014) and Haralambos and Holborn (2013) found that the symbolic interaction theory helps lecturers in university classrooms to be able to modify teaching to meet the learning needs of culturally diverse students through the use of differentiated instruction thus successfully manage diversity in classrooms. For lecturers to be able to do this, they must possess multiculturally competency. In two other separate studies by Mapolisa and Tshabala (2014) and Mandina and Chiheve (2015), results showed that social context symbols that lecturers use in classrooms that include gestures, words, labels, streaming, grouping and paying more attention to certain groups of students, can create either positive or negative emotions that affect learning in classrooms because of the types of emotions they create in students.

The words, gestures and labels teachers and students use on some students, the attention they give to other students and classroom management strategies the lecturers reflective the level of multi-cultural competency they possess (Dorrington \& Guy, 2018) and this has an effect on teaching and learning (see Figure 1). In their studies, Brown (2019) and Krasnoff (2016) found that classroom management activities such as building a caring and supportive classroom learning environment, setting a positive tone for all students as well as setting clear expectations to encourage all students from diverse cultural backgrounds to aim high lead to effective diversity management. Such contextual symbols are interpreted differently (subjectively) by the diverse students in the classrooms in a way that either facilitate or affect effective teacher-student and student-student interaction in the classroom thus affect learning and effective management of diversity in university classrooms in the end.

$H_{1}$ : There is a significant statistical relationship between implementation of CRPs in university classrooms and verbal and non-verbal communication.

$\mathrm{H}_{2}$ : There is a significant statistical relationship between implementation of CRPs in university classrooms and cultural knowledge of students by teachers.

$H_{3}$ : There is a significant statistical relationship between implementation of CRPs in university classrooms and classroom management.

$H_{4}$ : There is a significant statistical relationship between implementation of CRPs in university classrooms and effective student-teacher-interaction. 


\subsubsection{Culturally Responsive Pedagogies and diversity management}

Various studies have shown that for lecturers to be able to effectively manage diversity they should employ CRPs. Such pedagogies will ensure that teaching is effective and more personally appealing and meaningful to students, and that academic knowledge and skills development in students is situated within their lived experiences and frames of reference (Chinn, 2017; Dreyfus, 2019; Rhodes, 2016; Salmelo-Aro, 2017;). Furthermore, a study by Maasum et al (2014) also found that such teaching requires adequate knowledge by lecturers of cultural knowledge (cultural backgrounds) of all their students as a base or starting point, and should include the development of curricula that have cultural diversity elements in their content. Separate studies by Powell et al (2016), Farmer et al. (2016) and McKeown et al (2015) found effective management of diversity requires teachers to make pedagogic decisions and implement teaching approaches that (i) promote academic and social development of students, (ii) encourage teacher-student interaction, (iii) build teamwork aimed diverse students, and (iv) reduce competition in the classroom. These results are also confirmed in studies by Gest and Rodkin (2011) and Trussell (2008).

In their study also, Powell et al (2016:3) further found that to be able to effectively manage diversity through the use of CRPs lecturers need to possess adequate cultural knowledge, prior experiences, and frames of reference of their diverse students in order to make their learning encounters in classrooms more relevant and effective. In his study also, Krasnoff (2016) found that to be able to manage diversity in their classrooms through the use of CRPs, lecturers should employ approaches that satisfy the learning needs of different students' epistemologies particularly with regards to how students organize their world cognitively through their diverse language and symbols. Dorrington and Guy (2018) and Gay (2010) in their separate studies also found that for lecturers to effectively manage diversity in their classrooms, they need to employ multiple pedagogies in which they seek multiple perspectives from their students, acknowledge all their diverse students' comments, contributions and responses as well as use heterogeneous cooperative groupings to build teamwork among diverse students.

$H_{5}$ : There is a significant statistical relationship between implementation of CRPs in university classrooms and diversity management.

\section{Methodology}

\subsection{Research design}

The study employed a quantitative research design. The purpose of the quantitative research design in this study was to enable the research to discover how a selected large sample of lecturers think (Creswell, 2015) about the application of CRPs in universities. The use of the quantitative research design in this study "allows for a broader study, involves a greater number of subjects, enhances the generalization of the results and allows for greater objectivity and accuracy of results" (Creswell, 2015: 27). Stratified random sampling approach was used for selecting a sample of lecturers for the study. The purpose of stratified random sampling approach was to ensure that each population from the six universities is proportionately represented in the study (Creswell, 2015). There are 22 university in Zimbabwe from which six were selected using purposive sampling strategies. The six universities have been in operation for more than ten 
years and were considered possible rich sources of data based on how long they have been operating. Lecturers in the six universities represented the target population. A sample of 370 lecturers was selected to participate in the study. The Research Advisors (2006) online sample size table at 95\% level of confidence and $5 \%$ margin of error was used for coming up with the sample size from a combined target population of 3479 lecturers from the six universities. The distribution of 370 lecturers were as follows: $\mathrm{X} 1=51, \mathrm{X} 2=74, \mathrm{X} 3=47, \mathrm{X} 4=101, \mathrm{X} 5=64, \mathrm{X} 5=47$, and $\mathrm{X} 6=37$.

\subsection{Research instruments}

A self-constructed structured CRPs questionnaire was used for data collection in the study. The questionnaire consisted of 74 items from five factors as follows: Verbal and non-verbal communication-16, cultural knowledge-18 items, classroom management-11 items, Student-teacher interaction-12 items, and barriers to CRP implementation-17 items. Having 74 items for the five factors ensured that each of the factors related to the application of CRPs in universities was adequately researched on in the study. The purpose of using the quantitative approach was to allow for a broader study that involves a greater number of subjects, and that enhances the generalization of the results as well as allow for greater objectivity and accuracy of results (Creswell, 2015) with regards to the application of CRPs in universities.

The researcher used a questionnaire to ensure that a wide and diverse spectrum of lecturers in the universities was able to give their views on their use of CRPs to teach culturally diverse university students. The questionnaire was designed using the 5-point Likert scale from Strongly Agree (SA) - 5, Agree (A) - 4, Not Sure (NS) - 3, Disagree (DA) - 2 to Strongly Disagree (SDA) - 1. Since only words are used when designing the questionnaire, this means that the technique used for designing the questionnaire was qualitative while the data analysis was quantitative. A criterion mean (CM) of 3 which was the average of the scales was calculated for ease of analysis so that any mean score less than 3 showed disagreement with a given statement while a score from 3 and above showed agreement. 370 questionnaires were hand delivered to participants through the offices of deans of respective universities. 227 questionnaires were returned making a return rate of questionnaires of $(61.4 \%)$ for the lecturers.

The instrument was validated using Principal Component Analysis (PCA). PCA is defined as "the process of computing the principal components and using them to perform a change of basis on the data, sometimes using only the first few principal components and ignoring the rest" Eriksson, 2018: 12).PCA is therefore "commonly used for dimensionality reduction by projecting each data point onto only the first few principal components to obtain lower-dimensional data while preserving as much of the data's variation as possible" (Jaadi, 2019: 7). In the current study, (PCA) employed the orthogonal rotation procedure using varimax with Kaiser Normalization to summarize original data with minimum factors and maximum coverage (Lever, Krzywinski \& Altman, 2017; Jolliff \& Cadima, 2016). Items with factor loadings of less than .7 and eigenvalues of less than 1.0 were 
omitted from further analysis to improve data clarity in line with the assertion of Hair, Black, Babin \& Anderson (2010).

\subsection{Data analysis}

A number of data analysis tools were used in the study. Descriptive statistics for summarizing data through tables while One-way ANOVA, $t$-test and multiple regression analysis were used to determine the nature of relationships between the dependent variable and independent variables in the study.

\section{Results}

\subsection{Biographic profiles of lecturers}

Results in Table 1 show that more than half (57\%) of the lecturers are above 40 years which shows that the institutions are populated by fairly mature lecturers and this is also reflected in the years of experience where $62 \%$ of the lecturers have more than 10 years of experience. There are more male lecturers (55\%) than female $(45 \%)$ in the institutions which shows a problem of gender imbalance. Most of the lecturers have master's degrees (53\%) with $40 \%$ having doctoral qualifications and $12 \%$ having professional qualifications that include Chartered Institute of Management Accountants (CIMA) and Association of Chartered Certified Accountants (ACCA). This shows that universities still have challenges attracting doctoral qualifications holders and this may have ramifications on the lecturers' abilities to effectively teach and manage diversity at this level.

Table 1: Biographic characteristics of lecturers

\begin{tabular}{cccc}
\hline Biographic characteristics & Items & $\mathbf{N}$ & $\mathbf{\%}$ \\
\hline & $20-30$ years & 49 & 22 \\
Age & $31-40$ years & 48 & 21 \\
& $41-50$ years & 72 & 32 \\
Gender & $51+$ years & 58 & 25 \\
\hline Educational level & Male & 125 & 55 \\
& Female & 102 & 45 \\
\hline Years of teaching experience & Master's degree & 121 & 53 \\
& Phd degree & 91 & 40 \\
& Others, specify: ACCA, & 15 & 7 \\
& CIMA & & \\
\hline & Less than 5 years & 47 & 21 \\
& 5 - 10 years & 33 & 17 \\
& $11-15$ years & 74 & 33 \\
& $15+$ years & 66 & 29 \\
\hline
\end{tabular}




\subsection{Data validation using Principal Component Analysis}

Table 2: Principal analysis on independent variables

\begin{tabular}{|c|c|c|c|c|c|c|c|}
\hline Factors & $\begin{array}{l}\text { Mean } \\
\text { Values }\end{array}$ & SD & $\begin{array}{l}\text { Rotated } \\
\text { Factor } \\
\text { Loadings }\end{array}$ & $\begin{array}{l}\text { \% Variance } \\
\text { Extracted } \\
(\mathrm{VE})\end{array}$ & $\mathrm{KMO}$ & $\begin{array}{c}\text { Cronbach's } \\
\text { alpha }\end{array}$ & $\begin{array}{l}\text { Eigen } \\
\text { values }\end{array}$ \\
\hline $\begin{array}{l}\text { Verbal } \\
\text { communication }\end{array}$ & 3.81 & .723 & .736 & 49.713 & .806 & .788 & 3.441 \\
\hline $\begin{array}{l}\text { Cultural } \\
\text { knowledge }\end{array}$ & 3.97 & .649 & .911 & 59.127 & .725 & .815 & 2.095 \\
\hline $\begin{array}{l}\text { Classroom } \\
\text { management }\end{array}$ & 4.04 & .715 & .820 & 69.091 & .831 & .802 & 1.937 \\
\hline $\begin{array}{l}\text { Student-teacher } \\
\text { interaction }\end{array}$ & 4.36 & .625 & .738 & 62.827 & .793 & .751 & 1.519 \\
\hline $\begin{array}{l}\text { Barriers to } \\
\text { implementation } \\
\text { of CRPs }\end{array}$ & 4.15 & .701 & .820 & 63.550 & .804 & .811 & 2.883 \\
\hline $\begin{array}{l}\text { Total Variance } \\
\text { Extracted (VE) }\end{array}$ & & & & 57.629 & & & \\
\hline
\end{tabular}

Results in table 2 demonstrate the PCA done to validate the scale items. Using the SPSS Version 24, the PCA reduced the 74 scale items to 56 by removing all items whose factor loadings were less than .7 and eigenvalues less than 1.0. Results further show that the percentage variance extracted from the analysis nagged between $49 \%$ and $69 \%$ and also the total variance extracted (VE) of $57.6 \%$ demonstrated good convergence validity of the scale items. Furthermore, the positive correlation matrix between scale items was a good demonstration of adequate convergent validity of the scale items (Hair et al., 2017). Factor loadings that ranged between .736 and .911 as well as Cronbach's alpha values that ranged between .751 and .815 demonstrated the presence of good convergent validity (Hair et al., 2017). Cronbach's alpha values that ranged between .751 and .815 demonstrated good internal consistence reliability of the scale items. The KMO values which ranged between .725 and .831 demonstrated that sampling was adequately done.

\subsection{Application of CRP by university lecturers}

Table 3: Barriers to CRPs application in university classrooms

\begin{tabular}{llll}
\hline \multicolumn{1}{c}{ Item } & $\mathrm{N}$ & Mean & SD \\
\hline 1. I always try to respond to all students during teaching & 227 & 3.11 & .692 \\
2. I am always willing to learn from my students in & 227 & 2.66 & .680 \\
$\begin{array}{l}\text { terms of what they tell me, bring and show me in the } \\
\text { classroom }\end{array}$ & & & \\
3. I always have time to know more about my students & 227 & 2.37 & .871 \\
$\begin{array}{l}\text { and their personal experiences } \\
\text { I. I always plan and prepare ahead of class in order to } \\
\text { cater adequately for the different learning needs of all }\end{array}$ & & 4.11 & .793 \\
$\begin{array}{l}\text { my students } \\
\text { I always take time to reflect on my own experiences } \\
\text { and biases regarding the way I teach all my students }\end{array}$ & & & \\
\end{tabular}


6. I always use multiple teaching styles when teaching

diverse students in my class

7. I always use the lecture style when teaching 227

$\begin{array}{ll}4.01 & .751 \\ 3.01 & .706\end{array}$

8. I always respond positively and constructively to diverse students in my class

9. I always take time to know the diverse cultures in my class in order to use the cultural knowledge to connect what student know to new concepts and content

10. I always react quickly and positively to all my students' learning concerns

$\begin{array}{lll}227 & 2.11 \quad .637\end{array}$

11. I always respond readily, with interest and enthusiasm when diverse students have learning challenges

12. I use multiple, assessment methods for assessing diverse students in my class

13. I set clear expectations for diverse students to aim higher

14. I always ensure that the content I teach represents students' multiple cultures, genders, religions and nationalities

15. I always set rules for diverse students to work together in a supportive and cooperative manner

16. I always ensure equal access to learning opportunities 227 by diverse students

17. I have received professional training on the teaching and management of diverse classes

The criterion mean (CM) of 3.0 was used in this section to analyze the barriers to the application of CRPs by university lecturers with any mean less than 3.0 showing that the item is a barrier to the implementation of CRPs in universities. Results in Table 3 show that university lecturers faced a multiplicity of challenges that act as barriers to their effective implementation of CRP as well as management of diversity in their classrooms with the main challenge being that most of them have not received any professional training in the application of CRPs and management of diversity $(\mathrm{M}=1.01 ; \mathrm{SD}=.704)$. Other major challenges affecting how lecturers implement CRPs thus affecting how they manage diversity in their classrooms include the following: always willing to learn from their students during class $(\mathrm{M}=2.66$; $\mathrm{SD}=.680)$, not taking time to know more about their students and their personal experiences $(\mathrm{M}=2.37 ; \mathrm{SD}=.871)$, not taking time to reflect on their own experiences and biases regarding how they teach all their students $(\mathrm{M}=2.81 ; \mathrm{SD}=.705)$, not using multiple teaching styles when teaching diverse students in their classes $(\mathrm{M}=2.79$; $\mathrm{SD}=.686)$, not taking time to know the diverse cultures in their classes in order to use the cultural knowledge to connect what student know to new concepts and content $(\mathrm{M}=2.11 ; \mathrm{SD}=.637)$, not using multiple assessment methods for assessing diverse students in their classes $(\mathrm{M}=2.47 ; \mathrm{SD}=.652)$. Other challenges that act as barriers to effective implementation of CRPs in order to manage diversity in their classes include the following: not setting clear expectations for diverse students to aim higher 
$(\mathrm{M}=2.41 ; \mathrm{SD}=.693)$, not always ensuring that the content they teach represents students' multiple cultures, genders, religions and nationalities $(\mathrm{M}=2.49$; $\mathrm{SD}=.542)$, always using the lecture method for teaching $(\mathrm{M}=4.01 ; \mathrm{SD}=.751)$, and not always setting rules for diverse students to work together in a supportive and cooperative manner $(\mathrm{M}=2.15 ; \mathrm{SD}=.694)$.

\subsection{Correlation analysis}

Table 4: Correlation of independent and dependent variables

\begin{tabular}{|c|c|c|c|c|c|c|}
\hline & CA & VNC & CK & $\mathrm{CM}$ & SI & $\mathrm{BI}$ \\
\hline $\begin{array}{l}\text { CRPs application in } \\
\text { classrooms }\end{array}$ & 1 & & & & & \\
\hline $\begin{array}{l}\text { Verbal and non-verbal } \\
\text { communication }\end{array}$ & $.601^{* *}$ & 1 & & & & \\
\hline Cultural knowledge & $.663^{* *}$ & $.637^{* *}$ & 1 & & & \\
\hline Classroom management & $.614^{* *}$ & $.371^{*}$ & $.744^{*}$ & 1 & & \\
\hline Student-teacher interaction & $.782^{* *}$ & $.495^{* *}$ & $.388^{*}$ & $.519 * *$ & 1 & \\
\hline $\begin{array}{l}\text { Barriers to } \\
\text { implementation }\end{array}$ & $-.641^{* *}$ & $-.513^{* *}$ & $-.571^{* *}$ & $-.319 * *$ & $-.271^{* *}$ & 1 \\
\hline
\end{tabular}

Sig. ${ }^{*} p<.05 ;{ }^{* *} p<.01(2$-tailed $)$

CRPs application in classrooms (CA); Verbal and non-verbal communication (VC); Cultural Knowledge (CK), Student-teacher interaction (SI), Classroom Management (CM), Barriers to CRPs implementation (BI)

To measure the strength of association between independent variables and also between the dependent variable (CRPs application in classrooms) and independent variables (verbal communication, cultural knowledge, classroom management, student-teacher interaction, barriers to CRPs application), correlation analysis was performed. With regards to correlations between the dependent and independent variables, results in Table 4 show that studentteacher interaction has the highest positive correlation $(\mathrm{r}=.782 ; \mathrm{p}<.01)$ with CRPs application in classrooms which shows that effective student-teacher interaction improves CRPs application in classrooms. This is followed by cultural knowledge $(\mathrm{r}=.663, \mathrm{p}<.01)$ and classroom management $(\mathrm{r}=.614 ; \mathrm{r}<.01)$. Barriers to CRPs implementation has the highest negative correlation with CRPs application in the classroom which shows that as barriers increase, the ability of lecturers to apply CRPs in classrooms decreases.

With regards to the correlation between independent variables, results in Table 4 show that classroom management and cultural knowledge have the highest correlation $(\mathrm{r}=.744 ; \mathrm{p}<.05)$ showing that as the cultural knowledge of students by lecturers improve, so will also be their ability to manage their classes. The correlation between cultural knowledge and verbal and non-verbal communication is the second highest $(\mathrm{r}=.637, \mathrm{p}<.01)$ showing that cultural knowledge of students by lecturers leads to improvement in the way lecturers verbally and non-verbally communicate with their students. Barriers to CRPs implementation have a negative correlation with all the other independent variables showing that these barriers have an overall negative influence on the ability of lecturers to verbally communicate with diverse students $(r=-.513 ; \mathrm{p}<$ 
$.01)$, have adequate cultural knowledge of students ( $\mathrm{r}=-.571 ; \mathrm{p}<.01)$, manage diverse classes effectively $(\mathrm{r}=-.271 ; \mathrm{p}<.01)$, and also interact effectively with students from diverse cultures $(\mathrm{r}=-.319 ; \mathrm{p}<.01)$.

\subsection{Hypotheses testing}

Table 5: ANOVA on verbal and non-verbal communication and use of CRPs

\begin{tabular}{lcccccc}
\hline Variables & Source & $\begin{array}{c}\text { Sum of } \\
\text { squares }\end{array}$ & df & $\begin{array}{c}\text { Mean of } \\
\text { squares }\end{array}$ & F & Sig. \\
\hline $\begin{array}{l}\text { Non-verbal } \\
\text { communication }\end{array}$ & Within groups & 1027.61 & 3 & 342.54 & 6.053 & $.000^{*}$ \\
& Between groups & 11770.13 & 208 & 56.59 & & \\
$\begin{array}{l}\text { Cultural } \\
\text { knowledge }\end{array}$ & Wotal & 12797.74 & 211 & & & \\
& Within groups & 971.388 & 3 & 323.796 & 7.897 & $.003^{*}$ \\
& Between groups & 8529.612 & 208 & 41.001 & & \\
$\begin{array}{l}\text { Classroom } \\
\text { management }\end{array}$ & Within groups & 5501.000 & 211 & & & \\
& Between groups & 10631.441 & 208 & 51.113 & & \\
& Total & 11165.050 & 211 & & & \\
$\begin{array}{l}\text { Student-teacher } \\
\text { interaction }\end{array}$ & Within groups & 841.308 & 3 & 280.436 & 8.241 & $.003^{*}$ \\
& Between groups & 7146.151 & 210 & 34.029 & & \\
& Total & 7987.459 & 213 & & & \\
\hline
\end{tabular}

${ }^{*}$ Sig. $p<.05$

Results in Table 5 show that all the factors namely non-verbal communication, cultural knowledge, student-teacher interaction, and classroom management with effective implementation of CRPs in university classrooms $(p<.05$ for all cases). These results therefore show that all the four factors were predictors of effective implementation of CRPs in university classrooms.

Table 6: ANOVA on application of CRPs and management of diversity

\begin{tabular}{cccccc}
\hline Source & $\begin{array}{c}\text { Sum of } \\
\text { squares }\end{array}$ & $\mathrm{df}$ & $\begin{array}{c}\text { Mean of } \\
\text { squares }\end{array}$ & $\mathrm{F}$ & Sig. \\
\hline Within groups & 837.125 & 3 & 279.042 & 11.400 & .004 \\
Between groups & 5091.470 & 208 & 24.478 & & \\
$\quad$ Total & 5928.595 & 211 & & & \\
\hline
\end{tabular}

Sig: $p<.05$

Results in Table 6 show that there is a significant statistical relationship between effective use of CRPs and management of diversity in university classrooms ( $\mathrm{F}=$ $11.4 ; \mathrm{p}=.004 ; \mathrm{p}<.05)$. This shows that lecturers who are able to effectively apply CRPs in university classrooms have a high chance of being able to manage culturally diverse classes in universities. 
Table 7: Multiple regression model

\begin{tabular}{llllll}
\hline Model & $\mathrm{R}$ & R square & $\begin{array}{l}\text { Adjusted R } \\
\text { Square }\end{array}$ & $\begin{array}{l}\text { Std. } \\
\text { of Error } \\
\text { Estimate }\end{array}$ & $\begin{array}{l}\text { Durbin- } \\
\text { Watson }\end{array}$ \\
\hline 1 & $.701^{\mathrm{a}}$ & .4914 & .4853 & 1.2053 & 1.575 \\
\hline
\end{tabular}

Multiple regression analysis in Table 7 was conducted to establish the contribution of independent variables (biographic factors, multicultural competence and inhibiting factors) to variation in the application of CRPs in university classrooms. The results in Table 7 show that the Adjusted $\mathrm{R}^{2}$ is .4853 which shows that $48.53 \%$ of variations in the way university lecturers apply CRPs in their teaching of culturally diverse students is caused by the independent variables while the remaining $51.47 \%$ is as a result of extraneous variables outside the scope of this study.

\section{Discussion}

The purpose of the study was to establish factors influencing the implementation of CRPs as well as how significantly the application of CRPs influences diversity management in university classrooms. The study also identified factors that acted as barriers to effective implementation of CRP in universities. The symbolic interactionist theory by Cooley (1902) and Mead (1934) was used to guide the stud. The theory highlighted four dimensions namely verbal and non-verbal communication, classroom management, student-teacher interaction and cultural knowledge as being important for the implementation of CRPs.

It emerged in the study that verbal and non-verbal communication has a significant influence on the implementation of CRPs in universities. This means that what people understand or believe they understand from words and symbols that are communicated by the communicator has an influence on how they act or react in a particular situation. A study by Barker, Nyberg and Larsson (2019) found that different forms of communication produce emotions that result in different ways of behaving and acting, which have an influence, in the context of classrooms, on continued participation in learning by students. If some students believe that the communication being done by either the teacher or some sections of the class are demeaning to them or have some connotations of segregation, such students may end up not participating in the learning process at all or at worst, not coming to school. The words and symbols which teachers and students use for communicating may have a significant effect especially on how the marginalized students behave in the classroom. Confirming the above assertion, separate studies by Fitzpatrick (2018) and Frydendal and Thing (2019) found that subjective interpretations from a social context such as a classroom can contribute to positive emotions such as pleasure and excitement which facilitate learning or to negative emotions such as worry, nervousness, and shame among others, which disrupt learning. Another study by Dorrington and Guy (2018) also found that the words, gestures and labels that teachers and students use on some students as well as the attention they give to other students, have a significant influence on the levels of participation in the learning process by students who may feel affected or neglected. 
Results also showed that cultural knowledge of students by the teacher has a significant influence on the implementation of CRPs by university lecturers. Having a good understanding of the diverse cultures in the classroom helps lecturers to come up with teaching content and activities that cater for the needs of all students. To be able to understand how certain students learn and what they actually consider as learning, lecturers need to have a full understanding of the diverse cultures of these students. With this understanding, lecturers will then be able to make decisions on which teaching methods to use, how to select content to teach and what teaching tools to use. Lecturers who possess adequate knowledge of diverse cultures of students in the classroom are referred to as having multi-cultural competences who should mostly be able to use differentiated instruction as allowed for in CRPs (Dorrington \& Guy, 2018; Haralambos \& Holborn, 2013).

Results further showed that classroom management has a significant influence on the implementation of CRPs in university classrooms. Classroom management is important in the implementation of CRPs because it is about the decisions lecturers make and actions they take to create environments that are support and facilitate both academic and social-emotional learning. For students of diverse backgrounds to be able to learn effectively, certain conditions that make them feel safe, wanted, cared for and supported have to be in place. Studies by Farmer et al. (2016) and McKeown et al (2015) found that for lecturers to be able to engage diverse students in the learning proves, they need to establish conditions that elicit the cooperation of their students. Such conditions according to separate studies by Krasnoff (2016), Petty (2014) and Brown (2019) include all teaching in the classroom respects and represents multiple cultures, genders, religions and nationalities; being welcoming and focusing on students' strengths rather than weaknesses, providing students with clear criteria and standards for successful task completion; and setting clear rules on how students of diverse backgrounds interact in the learning process.

It further emerged in the study that student-teacher interaction has a significant influence on the implementation of CRPs. Allowing for opportunities where lecturers interact with their students as well as where students interact between and among themselves is very important in the implementation of CRPs and in encouraging all students to be involved in their learning. To provide opportunities for interaction between the lecturers and students and also between and among students themselves, lecturers need to use strategies such as class discussions and group discussions. Such groupings according to a student by Krasnoff (2016) need to be flexible for students of diverse cultures to be able to interact with each other and learn to understand and appreciate each other's different cultures.

Results of the study also showed university lecturers faced a number of challenges that affect effective implementation of CRPs to manage diversity in their classrooms due to the fact that most lecturers had not received training on how to 
implement CRPs. As a result of this lack of training, it was established in the study that most of the lecturers lacked multi-cultural competency.

\section{Conclusions}

Based on the above results, it was concluded that the implementation of CRPs in university classrooms in Zimbabwe was still work in progress owing to the myriad of challenges lecturers faced during the implementation of CRPs. These challenges ranged from a lack of understanding of the diverse cultures of the students, a lack of training in diversity management to failing to create supportive environments for students to learn. It was also concluded that classroom management, cultural knowledge, student-teacher interaction, and non-verbal communication had a significant influence on how CRPs was implemented by university lecturers. It was further concluded that effective implementation of CRPs in university classrooms was a pre-requisite for lecturers to be able to effectively manage diversity. This, according to reviewed literature, meant that for lecturers to be able to manage diverse in university classrooms through the application CRPs, they need to have adequate knowledge of the different cultures in their classes and the different CRPs they can utilize to be able to effectively manage and teach the culturally diverse students in their classrooms. This further means that lecturers for lecturers to be able to effectively apply CRPs to manage culturally diverse university classes, they must demonstrate multi-cultural competence by having adequate knowledge of cultural differences in their classes and how to use that knowledge to create learning environments that satisfy the learning needs of each of their students.

\section{Recommendations}

Based on the above results, it is recommend that university lecturers need urgent training on how they can apply CRPs to manage cultural diversity in classrooms to be able to make learning more meaningful and effective than currently. With adequate knowledge and skills of how to use CRPs to manage diversity, lecturers will become more confident, develop positive attitudes towards different cultures and will be able to prepare better for teaching culturally diverse students.

\section{Practical Implications of the study}

The study has implications on both practice and policy. With regards to practice, the study demonstrated that since university classrooms now consist of culturally diverse students, and that it is possible to successfully teach such students if lecturers use CRPs. These CRPs will ensure that individual learning needs of students from different cultures are catered for. With regards to policy, institutional management need to ensure that, as a matter of policy, lecturers use CRPs for teaching to ensure that they effectively teach culturally diverse students. Such a policy should also ensure that lecturers receive adequate training for them to be multi-culturally competent so as to be able to apply CRPs when teaching.

\section{Limitations of the study}

The study was quantitative in nature with the purpose of reaching out to as wide a number of lecturers as possible to solicit their views on the application of CRPs in universities. For more depth, a qualitative approach could also have been used 
as part of a mixed methods study. Further research therefore will require the use of a qualitative approach for more depth on the topic.

\section{Declarations:}

Informed consent: Informed consent was obtained from all participants before the commencement of the study.

Ethics approval and consent to participate: The study was given ethical approval and consent by the Bindura University of Science Education ethics committee.

Availability of data and materials: There is no date and material associated with this study to declare.

Competing interests: The researcher has no conflict of interest to declare in this study.

Funding: There is no funding to declare in this study.

Acknowledgements: The researcher wishes to send special acknowledgement to all lecturers from the participating universities who made this study possible.

Methods: methods used in the study were carried out in accordance with relevant guidelines and regulations.

\section{References}

Barker, D., Nyberg, G., \& Larsson, H. (2019). Joy, fear and resignation: investigating emotions in physical education using a symbolic interactionist approach. Sport, Education and Society, 25(8), 872-888. doi:10.1080/13573322.2019.1672148

Brown, C. (2019). 7 culturally responsive classroom management strategies. Retrieved from https://www.classcraft.com/blog/ on 19 September 2020.

Byrd, C. (2016). Does culturally relevant teaching work? An examination from student perspectives. SAGE Open.

Chinn, P. W. U. (2017). Why science education for diversity? Studies in Science Education, 53(1), 109-111.

Cho, H. (2017). Navigating the meaning of social justice, teaching for social justice, and multicultural education. International Journal of Multicultural Education, 19(2), 1-19.

Cooley, C. (1902). Human nature and the social order. New York: Scribner's.

Creswell, J. W. (2015). Educational research: Planning, conducting, and evaluating quantitative and qualitative research, 5 th ed. Boston, MA: Pearson.

Diaz, J., Suarez, C., \& Valencia, L. (2019). Culturally responsive teaching: A framework for educating diverse audiences. University of Florida: IFAS Extension.

Dorrington, A. E. L., \& Guy, L. (2018). It's not "just" good teaching: Cultural responsive teaching for educators (p. 5). National Education Student Program Webinar. Retrieved from https://www.google.com/search?safe=active\&sxsrfwiz on 7 February 2020.

Dreyfus, W. (2019). Teacher perceptions of culturally responsive pedagogy in the classroom. A doctoral thesis presented to the Graduate School of Education. Northeastern University, Boston, Massachusetts.

Eriksson, L. (2018). What is principal component analysis (PCA) and how it is used? Retrieved from https://blog.umetrics.com/what-is-principal-component-analysis-pcaand-how-it-is-used on 6 June 2020.

Essays UK. (2017). Functionalist conflict and symbolic perspectives on education. Retrieved from https://www.ukessays.com/essays/sociology/ on 4 May 2020.

Farmer, T. W., Chen, C. C., Hamm, J. V., Moates, M. M., Mehtaji, M., Lee, D., \& Huneke, M. R. (2016). Supporting teachers' management of middle school social dynamics: The scouting report process. Intervention in School and Clinic, 52(2), 67-76. doi:10.1177/1053451216636073 
Fitzpatrick, K. (2018). Poetry in motion: In search of the poetic in health and physical education. Sport, Education and Society, 23(2), 123-134.

Frydendal, S., \& Thing, L. F. (2019). A shameful affair? A figurational study of the change room and showering culture connected to physical education in Danish upper secondary schools. Sport, Education and Society, 1-12.

Gay, G. (2010). Culturally responsive teaching: theory, research, and practice (2nd ed.). New York, NY: Teachers College Press.

Gest, S. D., \& Rodkin, P. C. (2011). Teaching practices and elementary classroom peer ecologies. Journal of Applied Developmental Psychology, 32, 288-296.

Hair, J., Black, W. C., Babin, B. J., \& Anderson, R. E. (2010). Multivariate data analysis (7th ed.). Upper Saddle River, New Jersey: Pearson Education International.

Hair, J. F., Hult, G. T. M., Ringle, C. M., \& Sarstedt, M. (2017). A primer on partial least squares structural equation modelling (PLS-SEM) (2nd ed.). Thousand Oaks, CA: Sage.

Haralambos, M., \& Holborn, M. (2013) Sociology: Themes and perspectives ( $8^{\text {th }}$ ed). London: Harper Collins Publishers.

Hitchcock, C. H., Prater, M. A., \& Chang, C. (2009). Cultural competence: Developing and assessing multicultural proficiency for teachers and school personnel in Hawaii. Multicultural Learning and Teaching, 4(2), 1-24.

Jaadi, Z. (2019). A step by step explanation of principal component analysis. Retrieved from https:// builtin.com/data-science/step-step-explanation-principal-componentanalysis on 5 June 2020.

Jolliff, I. T., \& Cadima, J. (2016). Principal component analysis: a review and recent developments. Retrieved from https://doi.org/10.1098/rsta.2015.0202 on 5 June 2020.

Kahu, E., \& Nelson, K. (2018). Student engagement in the educational interface: Understanding the mechanisms of student success. Higher Education Research $\mathcal{E}$ Development, 37(1), 58-71.

Klen, R. (2015). In 10 Years, America's Classrooms Are Going to Be Much More Diverse Than They Are Now. The Huffington Post. Retrieved from on the Internet at www.huffingtonpost.com/2015/05/07/classroom-demographics2025_n_7175760.html on 21 January 2021.

Krasnoff, B. (2016). Culturally responsive teaching. A guide to evidence-based practices for teaching all students equitably. Region X Equity Assistance Center Education Northwest. Retrieved from https://educationnorthwest.org/sites/default/files/resources/culturallyrespo nsive-teaching.pdfRitzer. Accessed 15 November 2020

Ladson-Billings, G. (2014). Culturally relevant pedagogy 2.0: a.k.a the remix. Harvard Educational Review, 84(1), 74-84.

Lever, J., Krzywinski, M., \& Altman, N. (2017) Principal component analysis. Nat Methods $14,641-642$.

Levonius, D. (2016). Cultural Differences in the Classroom. Retrieved from https://www.td.org/newsletters/atd-links/cultural-differences-in-theclassroom on 21 January 2021.

Lodewyk, K. R., \& Muir, A. (2017). High school females' emotions, self-efficacy, and attributions during soccer and fitness testing in physical education. Physical Educator, 74(2), 269-295.

Maasum, T., Maarof, N., \& Ali, M. (2014). Addressing student diversity via culturally responsive pedagogy. Social and Behavioral Sciences, 134, 101-108.

Mandina, S., \& Chiheve, H. (2015). Teachers' and learners' perceptions of streaming and their impact on teaching and learning of principles of accounts at ordinary level 
in Masvingo urban district secondary schools. Social Sciences Research Journal, 2(1), 168-174.

Mapolisa, T., \& Tshabalala, T. (2014). The impact of streaming Zimbabwean secondary schools -learners attributes. Nova Journal of Humanities and Social Sciences, 2(3), 19.

McKeown, S., Stringer, M., \& Cairns, E. (2015). Classroom segregation: Where do students sit and how is this related to group relations? British Educational Research Journal, $42(1), 40-55$.

Mead, G. H. (1934). Mind, Self, and Society. Ed. by Morris, CW. Illinois, Chicago: University of Chicago Press.

Neill, J. (2017). Survey Research in Psychology. Retrieved from https://www.slideshare.net/jtneill/exploratory-factor-analysis on 14 June 2020.

Paris, D. (2012). Culturally sustaining pedagogy: A needed change in stance, terminology, and Practice. Educational Researcher, 41(3), 93-97.

Petty, L. (2014). How to Promote Equality \& Diversity in the Classroom. Retrieved from https://www.highspeedtraining.co.uk/hub/author/louise $/$ on 19 September 2020.

Powell, R., Cantrell, S. C., Malo-Juvera, V., \& Correll, P. (2016). Operationalizing culturally responsive instruction: Preliminary findings of CRIOP research. Teachers College Record, 118, 1-46.

Rhodes, C. (2016). Validation of the Culturally Responsive Teaching Survey. Adult Education Research Conference. Retrieved from http://newprairiepress.org/aerc/2016/papers/34_on 16 January 2019.

Richardson, C. (2018). Culturally Responsive Pedagogy in Teacher Education: Are We Adequately Preparing Pre-Service Teachers to Circumvent Cultural Marginality in the Classroom? Dissertation, Georgia State University. Retrieved from https://scholarworks.gsu.edu/epse_diss/121_on 3 January 2020.

Ritzer, G. (2014) Sociological theory. New York: Mc Graw-Hill Inc.

Rhodes, C. M. (2017). A validation study of the culturally responsive teaching survey. Universal Journal of Educational Research, 5(1), 45-53.

Salmelo-Aro, K. (2017). Dark and bright sides of thriving: School burnout and engagement in the Finnish context. European Journal of Developmental Psychology, 14(3), 337-349.

Simonton, K. L., \& Garn, A. (2018). Exploring achievement emotions in physical education: The potential for the control value theory of achievement emotions. Quest, 1-13.

Tarasawa, B. (2018). Three Research-based Culturally Responsive Teaching Strategies. Retrieved on 12 February 2019 from https:/ / www.nwea.org/blog/author/btarasawa/

Taylor, R. (2018). The Role of Culturally Responsive Pedagogy in the Preparation of Secondary Teacher Candidates for Successful Teaching of Diverse Learners: a Multiphase Mixed Methods Case Study. Dissertations and Theses. Paper 4255.

The Research Advisors. (2006). The Morgan Sample size table. Retrieved from http:// research-advisors.com/index.php on 23 March 2020.

Trussell, R. P. (2008). Classroom universals to prevent problem behaviors. Intervention in School and Clinic, 43, 179-185.

Wah, Y. L., \& Nasri, N. B. M. (2019). A Systematic Review: The Effect of Culturally Responsive Pedagogy on Student Learning and Achievement. International Journal of Academic Research in Business and Social Sciences, 9(5), 588-596.

Wrench, A., \& Garrett, R. (2015). Emotional connections and caring: Ethical teachers of physical education. Sport, Education and Society, 20(2), 212-227. 